\title{
Multimedia Platform Design of Table Tennis Teaching
}

\author{
Ying Xuan ${ }^{1}$, Chang Liu ${ }^{2}$ \\ ${ }^{1}$ Yunnan Sports Vocational College, Kunming, 650228, China \\ ${ }^{2}$ Yunnan Province Labour Unions Communist Youth League Women's Federation Cadre Training \\ School, Kunming, 650101, China
}

yingxuan2013@yeah.net

Keywords: multi-media technology teaching, sport education, table tennis theoretical

\begin{abstract}
Since the 1990s, mufti-media computer technology springs up promptly and develops vigorously. Its application has extended all over national economy and every aspect of social life and is bringing huge transform in human's production Way, Working way and even way of life. The paper has elaborated the related concept of multi-media technology and the theoretical basic, the pattern of multi-media teaching that utilized. For multi-media teaching as well as the challenge of soccer theoretical teaching. ASP, the widespread technology, is applied in the platform. It is developed with a view to both he teachers' needs and the students' needs to ensure the dependability, extendibility and transferability. The stability and transferability can, in the long run, meet the needs of teaching.
\end{abstract}

\section{Introduction}

"Multimedia" comes from the combination of "multiple" and "media". Different perspective has different descriptions for multimedia. Literally, multimedia is a variety of media, but it is often closely related to the computer, so the multimedia is mainly referring to the diversification of the computer to process information. Due to handle information, process or action of the procedure which can also be seen as the media, in this way, they all are multimedia tools, such as computer, TV and so on. Thus, broadly speaking, multimedia is a domain, which refers to the related techniques and methods for information processing, including broadcasting and telecommunications, household electrical appliances, printing etc. In the narrow sense, multimedia is used a computer to transfer text, graphics, images, sound, animation and film and television [1-2].

Based on computer network teaching mode "During teaching activities, students use the function of computer interactivity, first to communicate with other users (teachers, students, etc.) in the local area network (LAN) or local area network server, if the content cannot meet the requirements, here further apply for the wide area network to communicate the information with the further user or resource center [3]. This model can be easily to monitor all students and analyze the study result, thus learn the general level and individual differences of students, in order to timely adjust the teaching contents, methods and progress [4-6]. 21st century is the century of information technology; information is infiltrating every aspect of society by the unprecedented rapid momentum. Education informatization as an important content and index of cross-century education reform which have been included a new round of teaching plan in present world. Education informatization plan of our country has also started.

Table tennis theory of University sports major which the class hours are less than the practice hours, but more the teaching content. It is used the traditional teaching methods to teach, and the blackboard makes the teaching activities are confined to the classroom, in result information transmission efficiency is low; Textbooks are in text as information carrier, so the form is inflexible and the content is limited, so this kind of teaching form often produces only from the form to complete the teaching task, but only some superficial impression or dry knowledge on students, easy to forget and caused the teaching is low efficiency, poor effect, little information. However, the introduction of multimedia technology makes the traditional education teaching way has had the profound reform, for the multimedia information provided large information and widely range 
which can improve the efficiency and quality of education information in the limited time, and provide sound, imagines and pictures from multiple angles and across time and space in the classroom teaching, so that the students can use a variety of means to get all sorts of appearance, thereby enrich their own imagination, promote the formation of creativity, improve the learning efficiency and teaching effect and expand the students' information. Multimedia technology is obviously contributed in improving the teaching quality and teaching, and also has a huge promotion for the process of education reform and modernization education [7-8].

\section{Analysis and design for the requirements of table tennis teaching platform}

Based on web of Table tennis network teaching platform has been more mature, however, different network teaching platform is different design requirements and solutions with the teaching requirements and teaching environment. Based on the table tennis sports network teaching platform of database is decided by the actual situation and the existing management situation to develop a set of management information system software. In the physical network teaching platform, a computer is as the tool to process the sports venues, sports equipment, sports teaching, sports books and materials by man-machine interactive system, and timely and accurately reflect the current state of every work in the management of sports teaching, and use the historical data to statistical and analysis, in order to assist each department management of sports from the general perspective.

E-R drawing and data flow chart. E-R relation model as Figure 1 under sports network teaching platform:

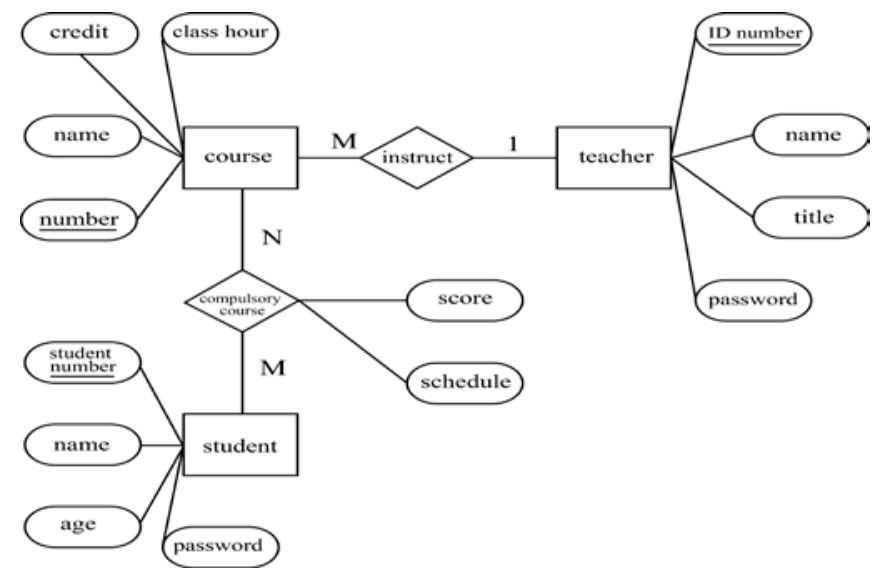

Figure 1 Entity relation drawing

Data flow chart as Figure 2 under sports network teaching platform:

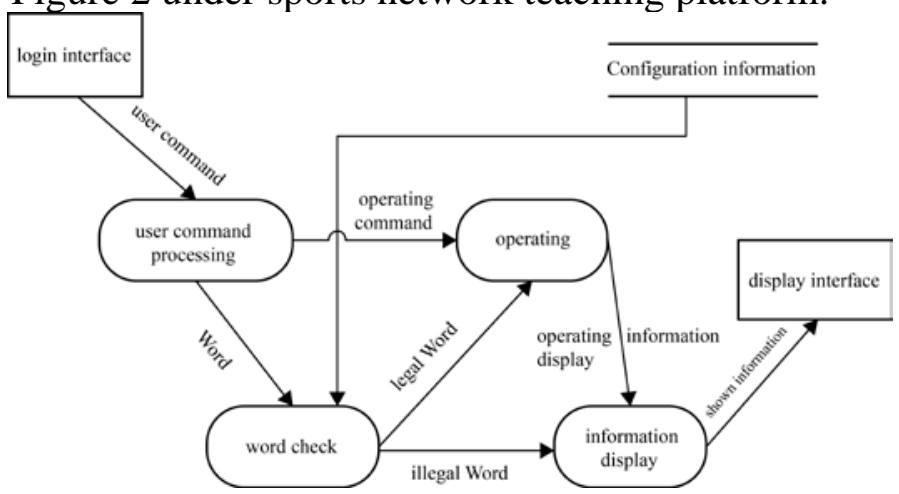

Figure 2 Data flow chart

The structure model of system implementation. Sports network teaching platform is an open platform for supporting teachers and students to realize the purpose of network teaching. Function modules of this teaching platform are designed two parts: teachers and students function module. General structure of the platform is shown in figure 3. 


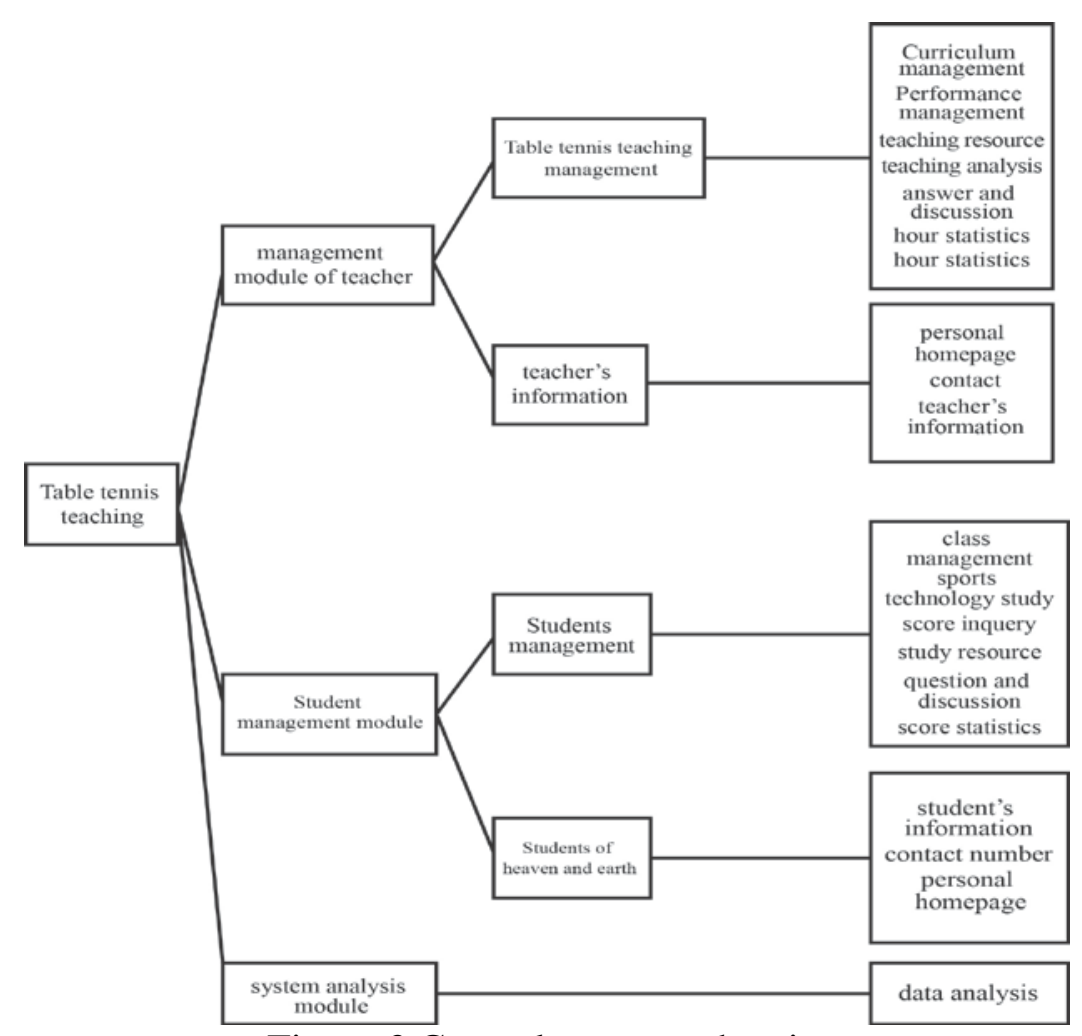

Figure 3 General structure drawing

\section{Realize of table tennis network teaching platform}

Managing model of table tennis teaching. Here use the curriculum management module of table tennis teaching management module as the example to introduce.in the part of taking the course, students can choose their favorite projects and appropriately modify for the wrong course within the prescribed period of time after the student login by the student ID and password. As shown in figure 4, the students can learn their favorite course and submitted from the school courses list. And they can also select again through the reset button.

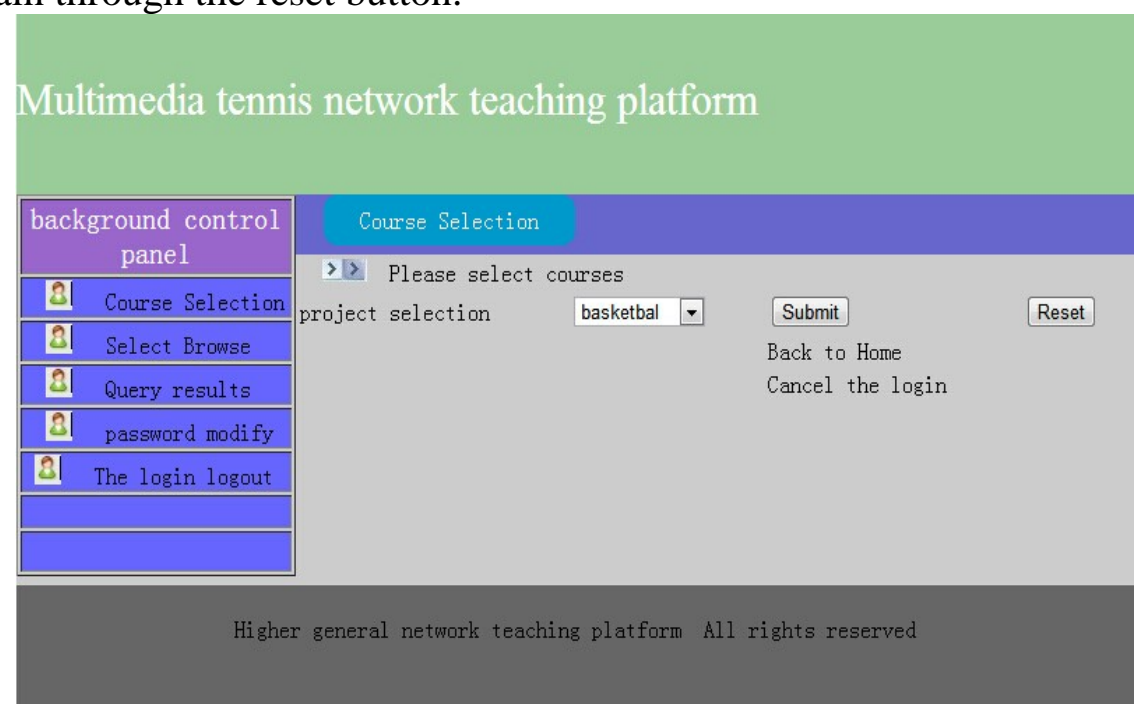

Figure 4 Management module of table tennis teaching

When the user enters into the page, first determine whether the user is legal or not, that is to say whether the user is logged in or the login is invalid or not. If the user is not legal , here shown "illegal user! Please login first" and a login link. If the user is legal that will enter the corresponding page. In the course selection page, first read the optional course name from the database and save them in the drop-down list, and the student user can choose the courses from the drop-down list, and then submit to the database to complete the course. The specific process as shown in figure 5: 


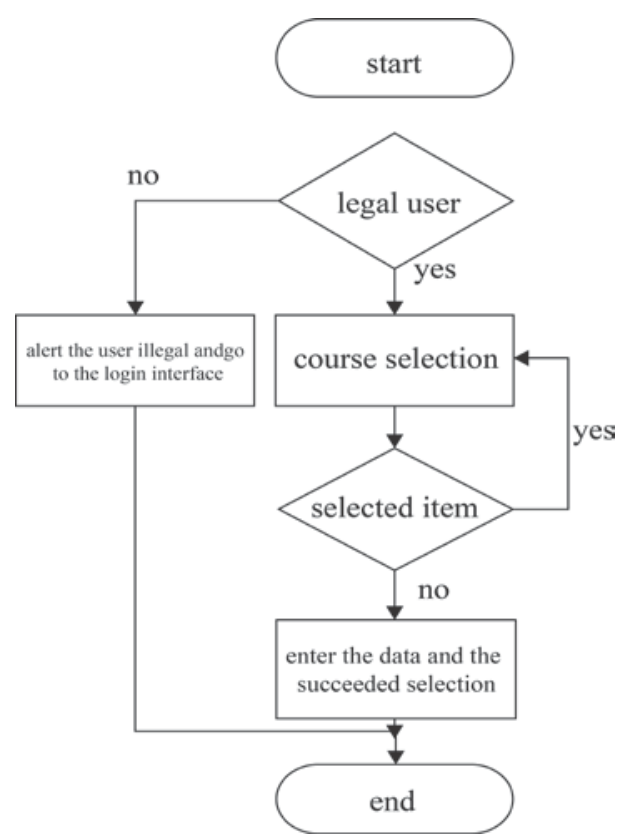

Figure 5 Selecting course flow chart

Learning management module of student. Score inquiry and discussion part, for example. In the management module of students learning, after the instructor inputs the scores into the system, here the students can login the system to query their scores, and teachers can also edit it in class to query the student's scores. As shown in figure 6.

\begin{tabular}{|c|c|c|c|c|c|c|}
\hline \multirow{3}{*}{\begin{tabular}{|c|c|}
$\begin{array}{l}\text { background control } \\
\text { panel }\end{array}$ \\
8| & Course Selection \\
8 & selection skim \\
\end{tabular}} & \multicolumn{6}{|c|}{ Query results } \\
\hline & \multicolumn{6}{|c|}{$>$ |>class: 508003} \\
\hline & student number & name & gender & class & sub ject & score \\
\hline \multirow{9}{*}{\begin{tabular}{|c|c|} 
S & Query results \\
\& & password modify \\
O & The login logout \\
\end{tabular}} & 50800301 & ZhaoDa & boy & 508003 & table tennis & 90 \\
\hline & s0800302 & CehenEr & girl & 508003 & ZhangSan & 95 \\
\hline & 50800303 & ZhangSan & boy & 508003 & table tennis & 80 \\
\hline & 50800304 & LiSi & girl & 508003 & table tennis & 70 \\
\hline & 50800305 & WangWu & boy & 508003 & table tennis & 65 \\
\hline & 50800306 & SongLiu & girl & s08003 & table tennis & 60 \\
\hline & $\mid$\begin{tabular}{||l|l|}
50800307 \\
\end{tabular} & LiuQi & boy & 508003 & table tennis & 95 \\
\hline & || 50800308 & QianBa & girl & s08003 & table tennis & 55 \\
\hline & 50800309 & ZhouJiu & boy & 508003 & table tennis & 90 \\
\hline
\end{tabular}

Figure 6 Score inquiry

Real-time communication is an important function in answering questions online and here through the interpretation of the teacher to improve the learning efficiency of the students. Realtime communications provides a real-time and discuss communication. Basic functions are similar with chat room, and here it inherited the merits of the traditional rooms, at the same time, teachers and students don't have to stick to traditional teaching way, and everyone can express their opinion and have a stronger discuss atmosphere. Therefore, this way is helpful to arouse the enthusiasm and subjective initiative of students.

\section{Conclusion}

It should be noted that sports network teaching has obvious improvement in physical education teaching effect and student's enthusiasm, but its itself also has some limitations and can not completely replace the traditional face-to-face education, here it can only be realized some parts of 
the sports teaching. Sports network teaching and traditional teaching have their own advantages, in accordance with the current hardware and software environment, the sports network teaching can't be existing as an independent form of teaching, which the role is only the complement and expansion of the traditional sports teaching. With the constant improvement of network and multimedia technology, the traditional sports teaching will be combined better with the network teaching, and sports network teaching platform will be more and more perfect.

\section{References}

[1] Fengzhen Qin. (2007) Implementation of tennis sports loading computer-aided system based on $\mathrm{B} /$ Smode Proceedings of the Sixth International Conference on Machine Learning and Cybernetics. IEEE Press, 4135-4138.

[2] Jiang-feng LI.(2006) Research and Application of Decision Support System Based on Data Mining and Online Analytical Processing.Hangzhou: Zhejiang university of technology, 58-59.

[3] Jing WANG. (2010) Design and Implementation of Technique and Tactics Information Analysis and Decision Support System for Table-Tennis. Computer Technology and Development, 20(2):6467.

[4] Wei-jie CAI, Xiao-hu ZHANG, Jianqiu ZHU. (2001) Survey of Association Rule Generation. Computer Engineering, 27(5):31-34.

[5] Guang-hong WANG, Ping JIANG.( 2004)Survey of Data Mining. Journal of Tongji University, 32 : (2) 246-253.

[6] Hayes.H (1998) Models for scholarly publishing in the 20th century, (22).

[7] Taylor.JC. (1997)Adualmode model of distance education: The University of Southern Queensland. Open Praxis. Vol 2:9-13. 